\title{
Robust Diagnosis of a Proton Exchange Membrane Fuel Cell Using Bond Graph Methodology - Physical and Electrical Faults Detection and Isolation
}

\author{
Abderrahmene Sallami ${ }^{*}$, Dhia Mzoughi', Hatem Allagui', Abdelkader Mami' \\ 1 Analysis, Design and Control Systems Laboratory, Faculty of Sciences of Tunis, Tunis El Manar University, \\ Tunisia \\ * Corresponding author's e-mail: abderrahmenesallami@gmail.com
}

\begin{abstract}
Fuel cells are currently experiencing an invigorating resurgence, both at the industrial and research levels. Diagnosis of stack performance is of importance for proton exchange membrane fuel cell (PEMFC) research. In this paper, a bond graph (BG) approach was used for modelling, simulation and robust diagnosis of a PEMFC. In literature, several PEMFC diagnosis methodologies were outlined in terms of efficiency and applicability. This paper described the linear fractional transformations (LFT) method to make it capable for handling the PEMFC diagnostics; an approach based on LFT-BG was developed to diagnose hydration and cells deterioration faults that may occur within a fuel cell. Simulation and experimental diagnostic testing results of a $1.2 \mathrm{~kW}$ Nexa fuel cell were presented and used to show the dynamic behaviour of the system variables and assessing the performance of the observer.
\end{abstract}

Keywords: robust diagnosis, bond graph approach, PEM fuel cell, linear fractional transformations, performance of the observer.

\section{INTRODUCTION}

Over the coming decades, hydrogen could be required to take a greater role in the field of energy, alongside electricity, responding to environmental concerns (global warming), but also in order to deal with the issue of energy independence inherent to the world's growing energy demand, and the need for more efficient energy chains. The fuel cell is considered as a very promising solution among the technologies considered for the future in terms of production of decentralized electrical energy. Fuel cell has been slow to reach its place in research and technology due to the issues related to materials and production techniques available. This is why its development was overshadowed by that of the thermal machines such as combustion engines, and that of turbo generators. Today, owing to significant investments in different sectors such as automotive and cogeneration, as well as the progress made in materials technology, new perspectives appear for the production of clean electricity through this means. The fuel cell is a powerful energy converter in terms of efficiency, which transforms the chemical energy contained in hydrogen into the electrical energy on the one hand and into heat and water on the other.

The diagnosis of uncertain systems has been the focus of much research work in recent years. This interest is reflected in the fact that natural systems are complex and non-stationary, while manufacturers seek greater safety and efficiency. The bond graph approach $[3,16,20,27]$ proposed in this paper allows - through its energy and multi-physics structure - to use a single tool for modelling, structural analysis and generation of uncertain analytical redundancy relations $A R R s$.

Given the complexity of the processes, the generation of residues is the most used way to alert 
the operator of the occurrence of an "abnormal" event. It is important to clarify the meaning given to the words used to evoke the malfunctions that may occur in the system. We retain, for this purpose, the definitions given in $[1,11,14,15,23]$.

In this work, we try to show how the bond graph approach can be used in modelling, simulation and construction of linear and nonlinear systems on the one hand, and the construction of system elements to be analyzed by graphics using the $L F T-B G$ on the other, to generate $A R R s$ $[4,7,8,9,13,18,21]$.

The remainder of the paper is organized as follows: section 2 briefly presents the fundamentals of the PEMFC, whereas section 3 discusses the PEMFC diagnosis, the $L F T-B G$ principle is given, the PEMFC bond graph model was introduced: two types of faults within it were considered, fault in the number of cells of the stack, and fault in the hydration rate of the PEMFC membrane. Some selected experimental and simulation results were shown in Section 4 and last section concludes the paper.

\section{DESCRIPTION OF THE PEMEFC}

The basic principle of a fuel cell was invented in 1839 by SirWilliam Grove. Itis thereverse principle of electrolysis: hydrogen combines with oxygen to produce water, electricity and heat $[10,12,17]$.

At the anode, the fuel (hydrogen) is dissociated into protons (or hydrogen ions $\mathrm{H}^{+}$) and electrons which generate an electric current according to the following oxidation reaction:

Anode side:

$$
H_{2} \rightarrow 2 H^{+}+2 e^{-}
$$

At the cathode, oxygen, protons and electrons recombine to form water, which hydrates the membrane according to the following reduction reaction:

Cathode side:

$$
2 \mathrm{H}^{+}+2 e^{-}+\frac{1}{2} \mathrm{O}_{2} \rightarrow \mathrm{H}_{2} \mathrm{O}
$$

While the electron transfer takes place through an external electrical circuit, the membrane acts as an ion-junction bridge allowing protons to transit from the anode to the cathode and thus close the electrical circuit. The overall reaction is finally written as follows:

Overall reaction:

$$
\mathrm{H}_{2}+\frac{1}{2} \mathrm{O}_{2} \rightarrow \mathrm{H}_{2} \mathrm{O}+\text { Electricity }+ \text { Heat }
$$

This reaction creates a potential difference between the electrodes of the order of one Volt, a potential difference that is specific to the redox couple formed by $\mathrm{H}_{2}$ and $\mathrm{O}_{2}$. Due to this very low naturalness voltage, manufacturers assemble several cells in series to achieve a sufficiently high voltage with a satisfactory yield. A fuel cell then constitutes a stack of elementary electrochemical generators called cells between two end-plates

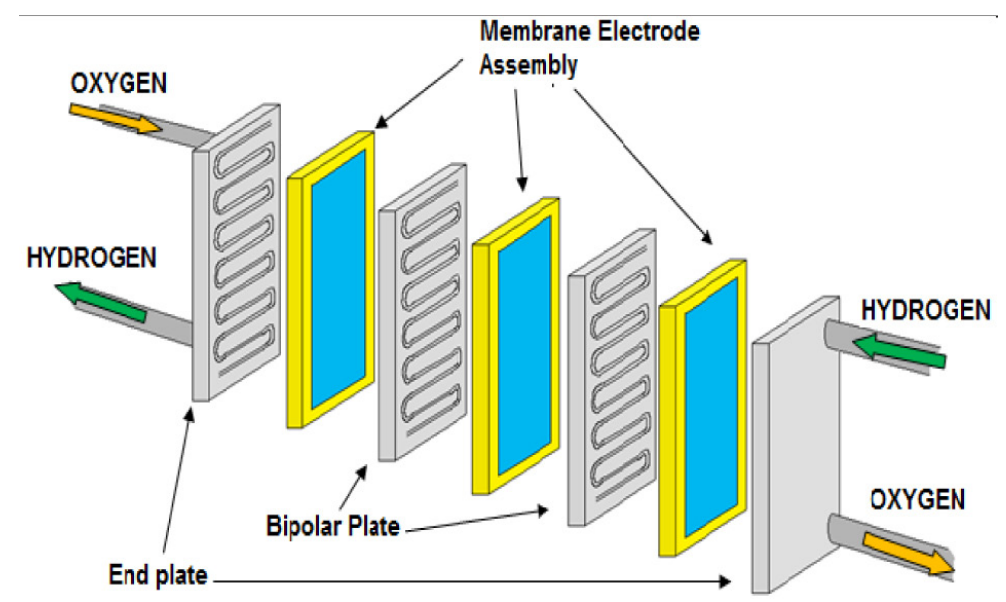

Fig. 1. Exploded view of a PEMFC supplied with hydrogen and oxygen 
used for supplying and which constitute the electrical terminals of the fuel cell, as shown in Figure 1.

Fuel cells are clean, as they operate on the reverse principle of water electrolysis and only emit water and unconsumed reactant gases.

The total oxide-reduction reaction (Eq. (3)) is exothermic: at $25^{\circ} \mathrm{C}$, the free enthalpy of the reaction is $-237 \mathrm{~kJ} / \mathrm{mol}$ or $-229 \mathrm{~kJ} / \mathrm{mol}$, depending on whether the water formed is liquid or gaseous.

Figure 2 shows the static polarization curve of a PEM fuel cell. The different losses (activation, ohmic and concentration) are present at all values of the current with various preponderances.

This static characteristic is important in evaluating the performance of the fuel cell. It depends on several parameters: the hydration of the membrane and its thickness, the type of catalyst, and the operating parameters (temperature and pressure). The typical operating temperature ranges between $60^{\circ} \mathrm{C}$ and $80^{\circ} \mathrm{C}$.

Indeed, the diagnosis is performed on-line on a sliding window using the PEMFC output voltage as the only measurement.

\section{PEMFC DIAGNOSIS}

Fuel cells are governed by multiple physical phenomena and various technology components, so the bond graph approach, based on an energy analysis and multi-physics, is well suited.

The bond graph modelling tool was defined by Paynter [21]. This approach allows energy to highlight the analogies between the different areas of physics (mechanics, electricity, hydraulics, thermodynamics, acoustics, etc.) and represent

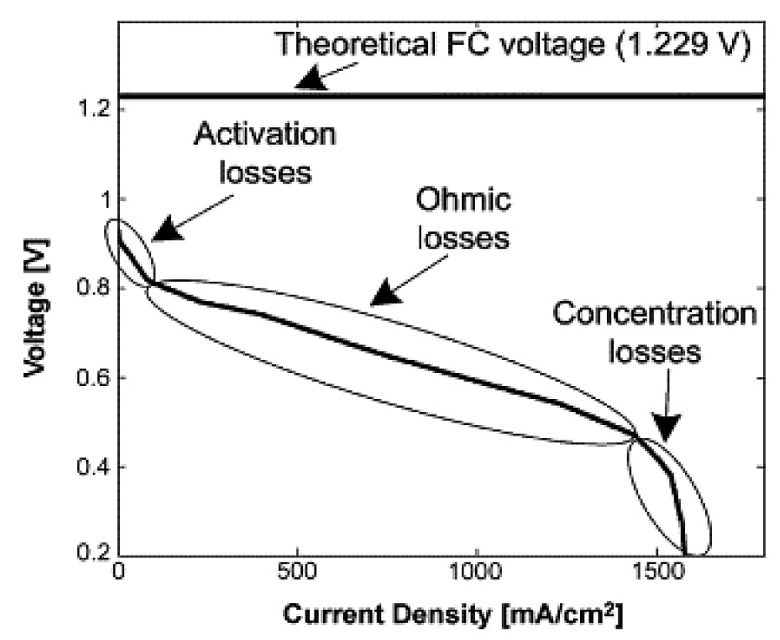

Fig. 2. Typical fuel cell polarization curve them in a uniform multidisciplinary physical system $[2,5,18,25,26,27]$. The bond graph formalism constitutes an explicit graphical tool for modelling of complex multidomain systems and describing energy exchanges within a system. Bond graphs allow a unified representation of the laws of the different areas of physics; they are multi-energy domain (mechanical, electrical, hydraulic, etc). Bond graph provides a detailed understanding of the dynamics of the physical systems; moreover, it can facilitate multidisciplinary exchanges.

Bond graphs have a notion of causality which provides a tool for the intuition-based discussion of system behaviour (controllability, observability, etc). A fundamental property of a bond graph model relates to the conservation of the junction structure, which in the context of a fuel cell system ensures that the different conservation laws are always correctly represented.

The process of diagnosis, generating residues calling analytical redundancy relations from linear mono-energy bond graph model, is addressed in [6] according to the causal paths. At the junction structure level (junctions $0,1, T F$ and $G Y$ ), several relations between different flows and efforts can be established.

\section{Fractional linear transformations representation}

Different models for the generation of fault detection and isolation procedures for industrial systems were adopted and developed. Among these models, there is the fractional linear transformation (LFT) model. This model is a generic concept widely used in uncertain instruction modeling for industrial systems. They consist in separating the nominal part of a model from its uncertain part, as shown in Figure 3a.

In this paper, we used the bond graph tool as an integrated language for modeling and robust error detection and isolation using the fractional linear transformation form for the generation of redundant analytic relationships. These redundant analytic relations consist of two perfectly separated parts, a nominal part called residue $r_{n}$ describing the operation of the system, and an uncertain part called $d$.

The innovative interest of this paper is the use of the bond graph approach for modeling, robust diagnosis and residual sensitivity analysis, taking into account the uncertainties of the parameters in Figure 3b. 

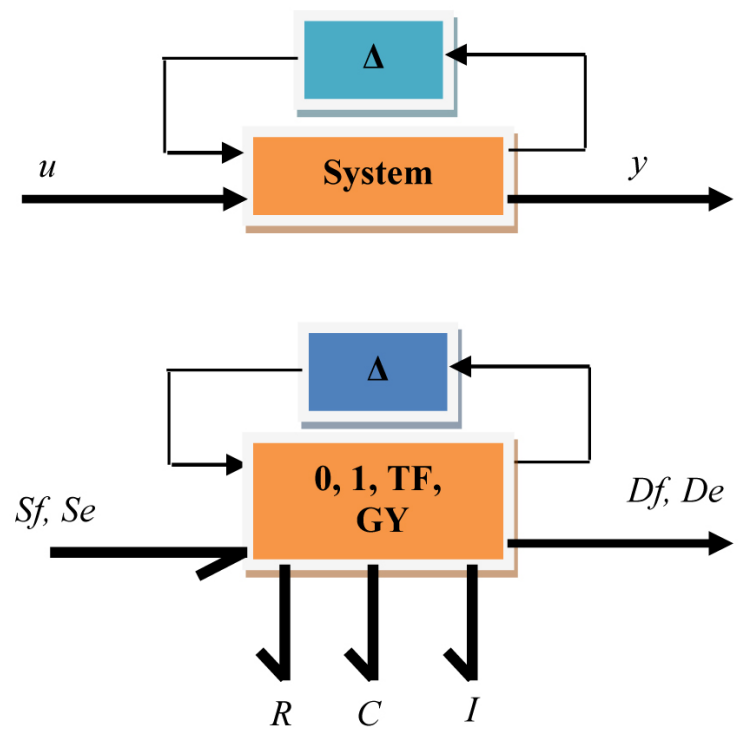

Fig. 3. a) LFT model, b) Bond graph using LFT

\section{Uncertain diagnosis of the PEMFC}

The primary purpose of the work was to apply an electrical fault at the membrane resistance $R S$, which is an active resistance related to both the electrical part (resistive behaviour whose nonlinear characteristic follows a Butler-Volmer law) and the thermal part as heat sources, and other physical fault at the transformer element $T F$ corresponding to a simple gain equal to the number of the stack cells models the total flow received by the component.

The electrolyte appears as a solid membrane of a typical thickness of a hundred micrometers $(100 \mu \mathrm{m})$. This membrane must have the following properties:

- be a good ion conductive for the movement of protons $H^{+}$

- be a good electrical insulator;

- be impermeable to hydrogen and oxygen gas;

- have good mechanical resistance towards thermal, pressure and hydration stresses.

The conductivity of the membrane mainly depends on its temperature and its degree of hydration. The latter is critical in the implementation of a fuel cell. From there comes the idea of considering the fault in the hydration rate (usually noted $\lambda_{m}$ ). The membrane hydration rate is representative of the number of water molecules present at each site consisting of a sulfonate-terminated.

In order to design a fuel cell corresponding to the specifications for a given project, the designer has two degrees of freedom, the number $N$ of cells in series which fixes the stack voltage and the surface $S$ of a cell which fixes the stack current. In this paper, particular attention was paid to the number of cells reflected by the $T F$ element and faults that may emerge.

The physical fault consists in introducing a fault at the cells i.e. when cells are damaged, the voltage decreases. For the electrical fault, it consists in applying a strong current which directly affects the hydration rate and therefore affects the membrane resistance (dry out the membrane). Figure 4 shows the PEMFC bond graph submodel, developed in [19], subjected to a physical and electrical fault at the electrolyte layer.

The bond graph approach enables to clearly view this type of fault which is reflected in the deterioration of cells modeled by $T F$ element as well as the dryness of the membrane modeled by the $R S$ element.

Faults which may affect the PEM fuel cell are of two types:

- Fault caused by overvoltage (or undervoltage): the cells generate an overvoltage at the PEMFC when they are in significant numbers or an undervoltage when they are in low numbers

- Fault caused by overcurrent (or power shortage): when connecting the PEMFC to a substantial electrical load, an overcurrent occurs and which causes the dryness of the fuel cell; and when connected to an insubstantial electric charge, a power shortage is detected causing the flooding of the PEMFC. 


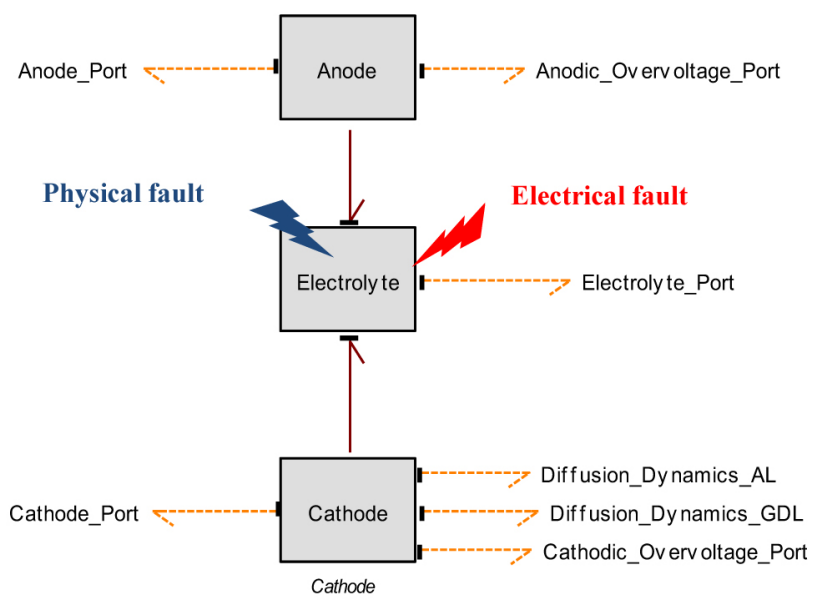

Fig. 4. Exploded view of the PEMFC bond graph submodel

\section{Determination of the residue of the TF-junction}

The $T F$ junction is affected by a physical fault, as shown in Figure 5; this fault is resulted in the determination of the residue equation $R_{l}$ by the ARR with LFT-BG.

The $L F T-B G$ model of the PEMFC membrane in integral causality is given in Figure 6 along with the $T F$ element in integral causality. The $L F T-B G$ model of the PEMFC membrane in derivative causality is given in Figure 7 with the $T F$ element in derivative causality and dualization of the flow sensor $D f_{T F}$.

The residue $R_{l}$ provides the equation below:

$$
R_{1}=r_{1 n}+d_{1}
$$

$$
\begin{aligned}
& R_{1}=e_{4}+e_{5} \quad e_{3} \quad e_{6} \\
& =e_{a n}+e_{c a} \quad m_{n} \cdot\left(e_{\text {out }} \quad w_{b}\right) \\
& \Phi\left(R S, f_{7 R S}\right) \cdot S S f_{T F} \\
& r_{\text {ln }}=e_{\text {an }}+e_{c a} \quad m_{n} \cdot e_{\text {out }} \\
& \Phi\left(R S, f_{7 R S}\right) S S f_{T F} \\
& \left|d_{1}\right|=m_{n} \cdot w_{b}
\end{aligned}
$$

Where $r_{1 n}$ is the normal residue,

$d_{1}$ is the parameter uncertainty;

$S S F_{T F}$ is a sensor flow related to the dualized $T F$ element,

$e_{a n}$ is the effort related to the anode,

$e_{c a}$ is the effort related to the cathode,

$e_{\text {out }}$ the output voltage.
From this equation we can notice that the residue $R_{l}$ depends on the transformation ratio $\left(m_{n}\right)$ in both operating modes, i.e. in the normal operating mode (Eq. 6) and the abnormal operating mode (Eq. 7).

\section{Determination of the residue of the RS element}

For the Nexa PEMFC, on which we have performed measurements, the electrolyte consists of a Nafion membrane. The conductivity of the $\mathrm{Na}$ fion depends essentially on two parameters: the temperature and its rate of hydration. The RS element is affected by an electrical fault, as shown

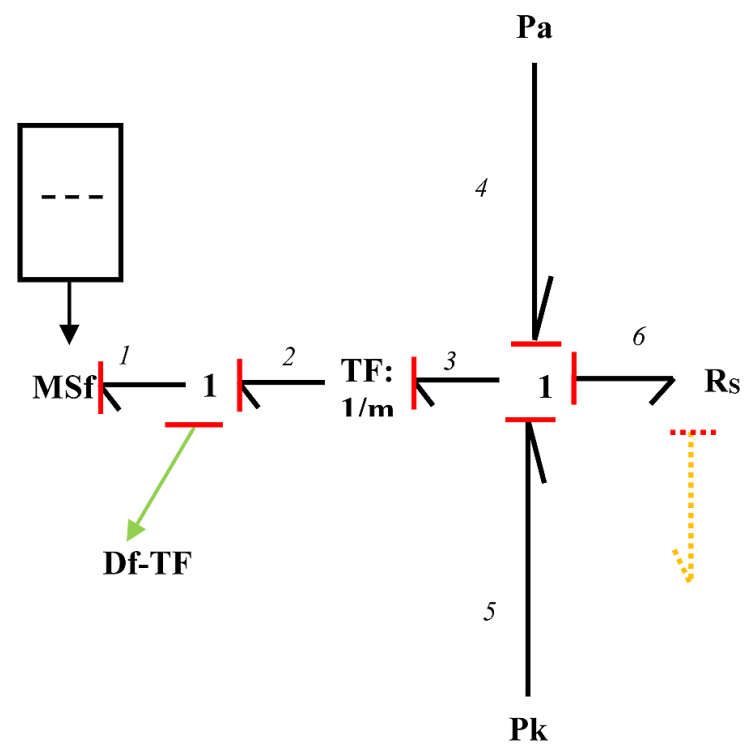

Fig. 5. Bond graph model of the PEMFC membrane with physical fault applied to a TF element 


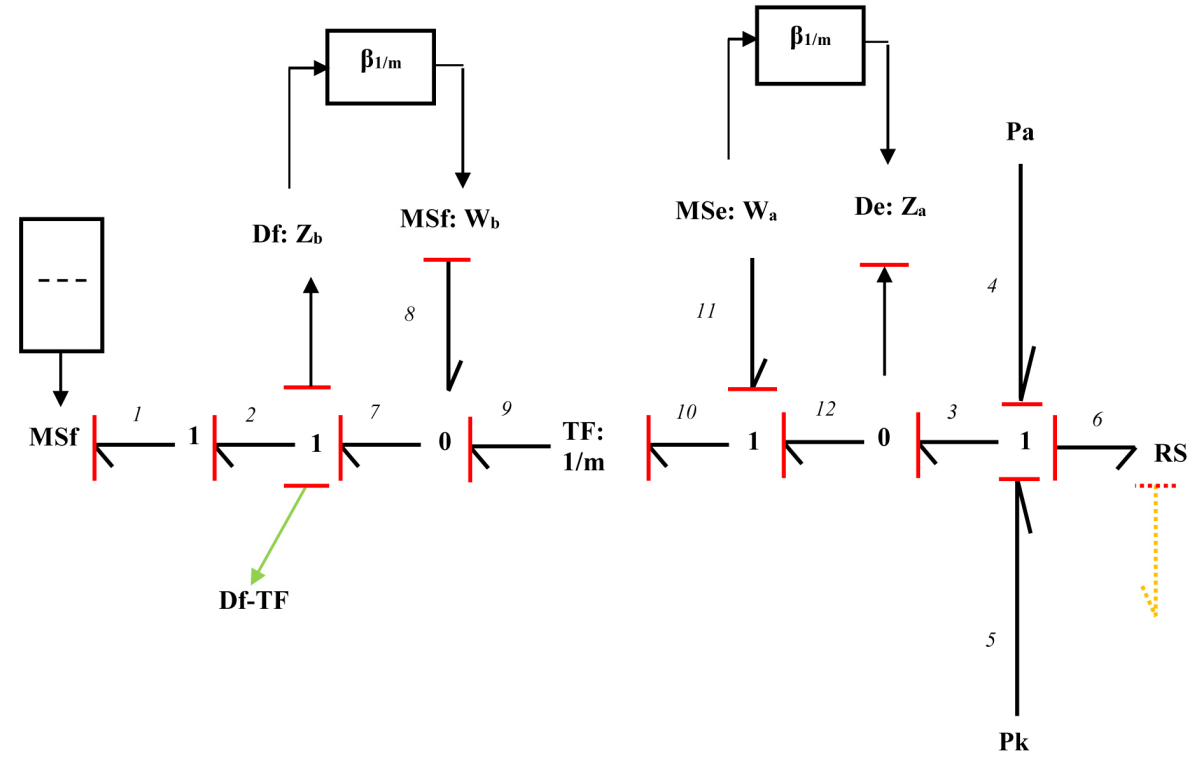

Fig. 6. LFT-BG model of the PEMFC membrane with flow (current) sensor

in figure 8 , this fault is reflected in the determination of the residue equation $R_{2}$ by the $A R R$ with $L F T-B G$.

The $L F T-B G$ model of the PEMFC membrane in integral causality is also given in Figure 9 with the $R S$ element in integral causality. The LFT-BG model of the PEMFC membrane in derivative causality is given in figure 10 with the $R S$ element in derivative causality and dualization of the flow sensor $D f_{R S}$. The $R S$ element is affected by an electrical fault; this fault is resulted in the determination of the equation of the residue $R_{2}$ by the $A R R$ with $L F T-B G$. The residue $R_{2}$ provides the equation below:

$$
R_{2}=r_{2 n}+d_{2}
$$

$$
\begin{aligned}
R_{2} & =e_{4}+e_{5}-e_{2}-e_{3} \\
& =e_{a n}+e_{c a}-\Phi\left(R S_{n}, e_{R S}\right) \cdot\left(1+\beta_{\frac{1}{R S}}\right)
\end{aligned}
$$

with

$$
\begin{gathered}
r_{2 n}=e_{a n}+e_{c a}-m \cdot e_{o u t} \cdot S S f_{R S}-\Phi\left(R S_{n}, e_{R S}\right) \\
=e_{a n}+e_{c a}-m \cdot e_{R S} S S f_{R S}-f_{2 R S_{n}} \\
\left|d_{2}\right|=\Phi\left(R S_{n}, e_{R S}\right) \cdot \beta_{\frac{1}{R S}}=f_{R S_{i n c}}
\end{gathered}
$$

where $r_{2 n}$ is the normal residue, $d^{n}$ is the parameter uncertainty, $S S F_{R S}$ is a sensor flow related to the dualized RS element, $e_{a n}$ is the effort related to the anode, $e_{c a}^{a n}$ is the effort related to the cathode, $e_{\text {out }}$ the output voltage.

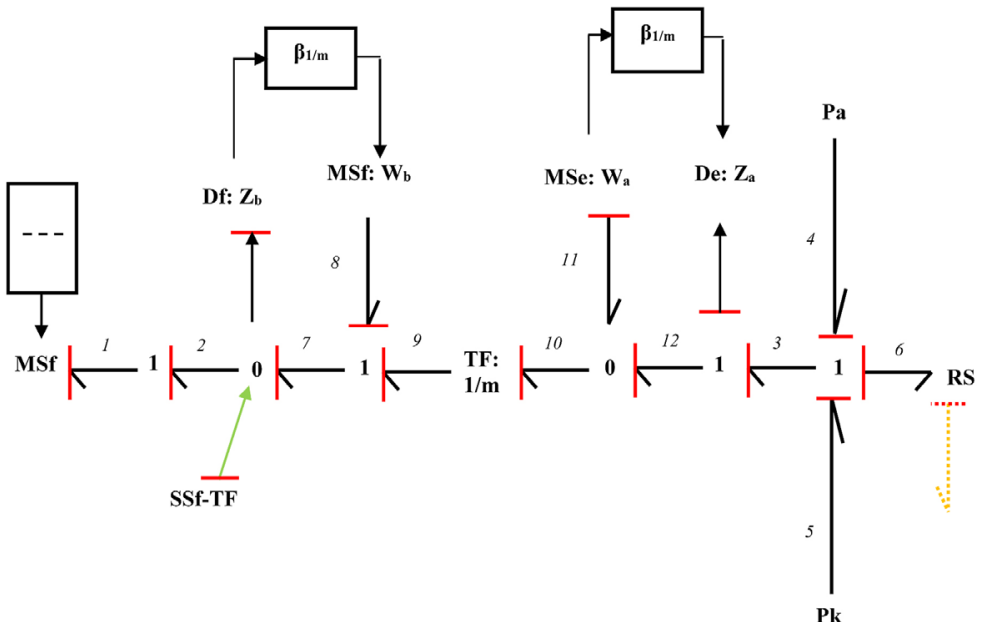

Fig. 7. LFT-BG model of the PEMFC membrane with dualized flow (current) sensor 
From this equation we can notice that the residue $R_{2}$ is a compound equation, it depends on $R S_{n}$ and effort $e_{R}$, in both operating modes, i.e. in the normal operating mode (Eq. 10) and the abnormal operating mode (Eq. 11).

\section{RESULTS AND DISCUSSIONS}

The Nexa PEM fuel cell system which provides up to $1200 \mathrm{~W}$ of unregulated DC power at a nominal output voltage of $26 V D C$ was used for testing. The PEMFC is composed of 47 elementary cells in series. The pressure of hydrogen and oxygen is about 5 bar and the operating temperature is $338.15 \mathrm{~K}$. We also used an electronic load supporting a $25 \mathrm{~A}$ current.

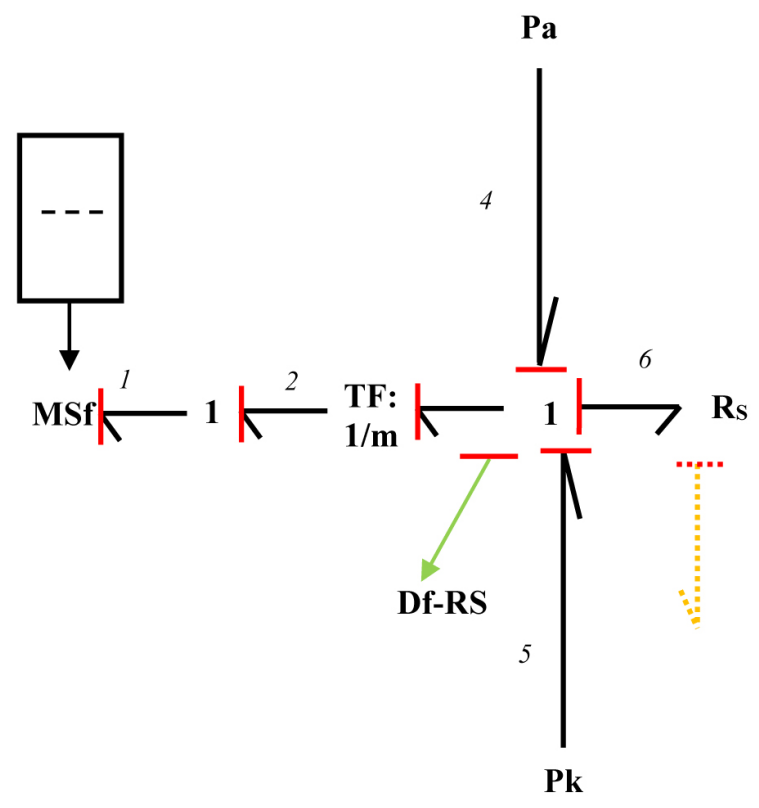

Fig. 8. Bond graph model of the PEMFC membrane with electrical fault applied to RS element
In the simulation process, firstly, the objective is to observe and evaluate the behaviour of the proposed bond graph model of the PEMFC on which faults will be applied; and secondly, compare the results obtained with simulation to those obtained experimentally.

Simulation results were obtained using the 20sim software (University of Twente, Enschede, Netherlands), which is developed by Controllab. 20 -sim is a modelling and simulation program for multidomain dynamic systems; models can be entered as bond graphs, equations, block diagrams and physical components. 20 -sim is widely used for simulating and analyzing the behaviour of multi-domain dynamic systems and creating control systems [28].

Figures 11 and 12 show the evolution of the voltage versus current (experiment and simulation) in cases of overvoltage (Figure 11) and under-voltage (Figure 12).

It was observed that the agreement between experimental and simulated data is very good and confirm the mathematical equations previously determined, Eqs. (6) and (7). If the stack features a large number of cells, there will thus be an overvoltage, and an under-voltage in the case where cells were damaged; and this was confirmed by the results presented in the curves shown in Figures 11 and 12.

Figures 13 and 14 show the evolution of the voltage versus current (experiment and simulation) in cases of over-current (Figure 13) and power shortage (Figure 14).

It can be seen that the simulation results agree well with the measured data and also confirm the previously determined mathematical equations, Eqs. (10) and (11).

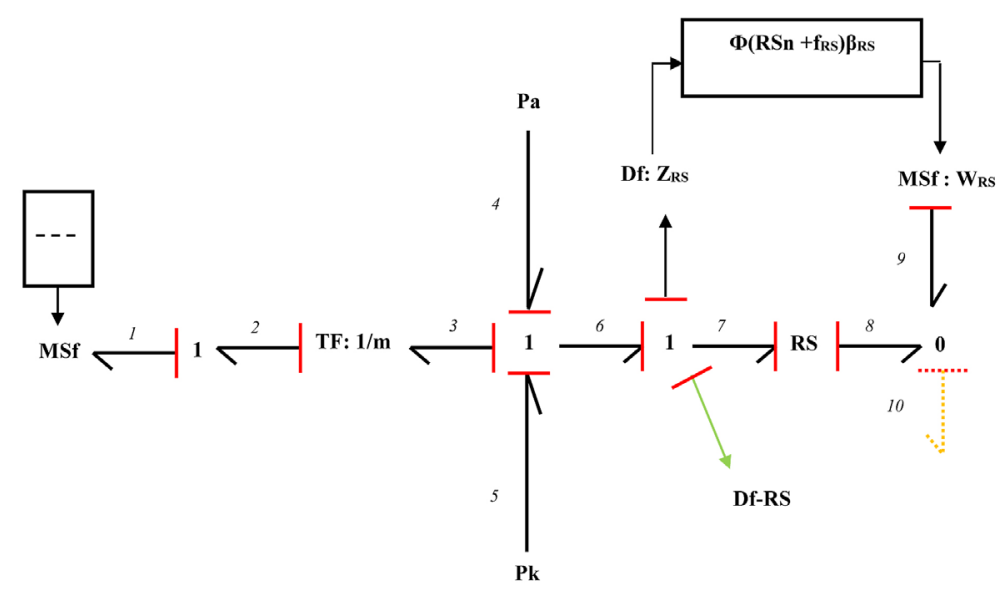

Fig. 9. LFT-BG model of the PEMFC membrane with flow (Entropy flow) sensor 


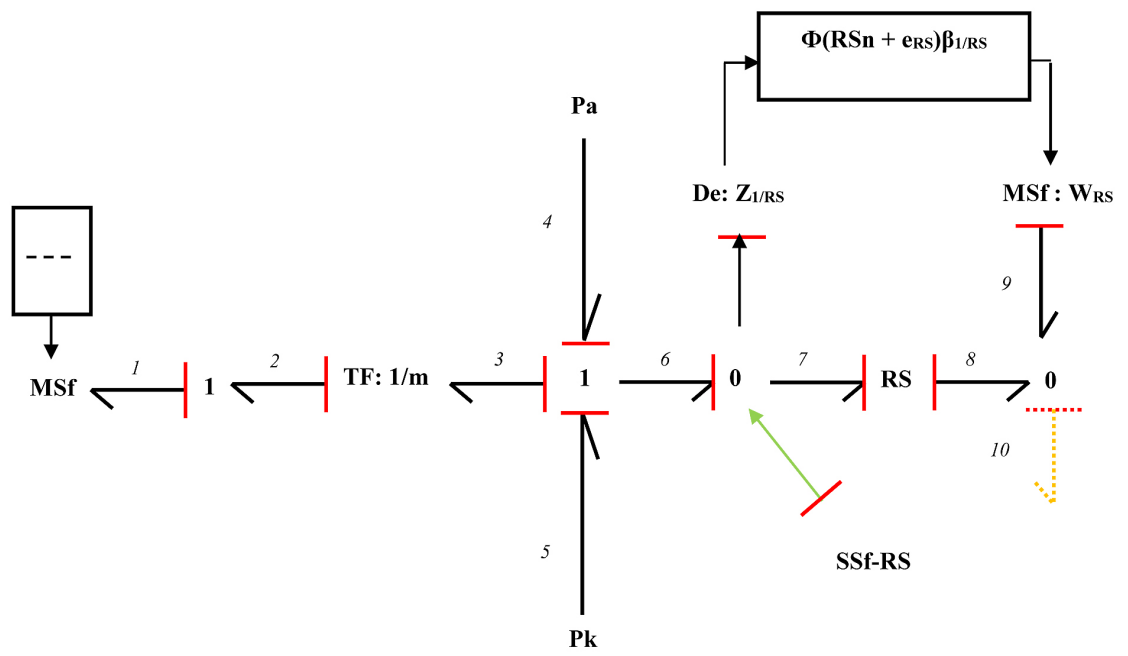

Fig. 10. LFT-BG model of the PEMFC membrane with dualized flow (temperature) sensor

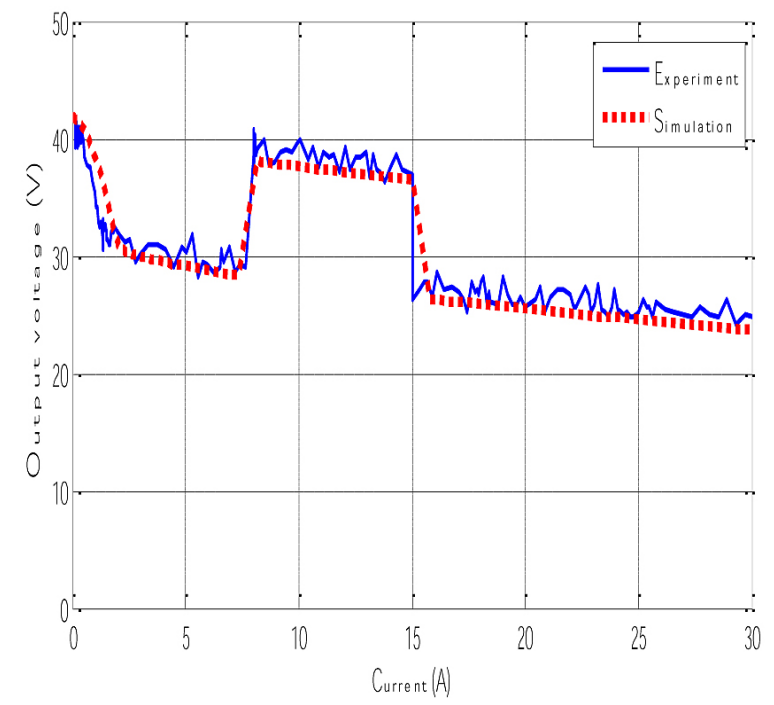

Fig. 11. Polarization curve of $1.2 \mathrm{~kW}$ Nexa fuel cell with fault in TF element due to an overvoltage

As we mentioned previously, the faults which may affect the PEMFC are of two types, one is caused by overvoltage or under-voltage, and the other is caused by over-current or power shortage. We modeled these faults by bond graph approach and we clearly defined their origin. In fact, for the first fault: it is related to the number of cells in the stack, this number is modeled through the transformation ratio $m$, the fault is shown by the $R_{1}$ residue having a part that reflects the changes in normal residue $r_{I n}$ and a related part to parameter uncertainty $d_{l}$. In turn, the second fault is related to the hydration rate of the PEMFC $\lambda_{m}$, the fault is evidenced by the $R_{2}$ residue having a part that reflects the changes in normal residue $r_{2 n}$ and a related part to parameter uncertainty $d_{2}$.
The originality of the bond graph approach is that we can determine the equation of the residue by separating the nominal part relative to the uncertainty.

\section{CONCLUSIONS}

The industrial diagnosis processes are generally characterized by analyzing the robustness of residues to uncertainties and faults. The Linear Fractional Transformations (LFT) for modelling parametric uncertainties of fuel cells with bond graph approach $(L F T-B G)$ generated systematically the indicators of the robust residues. These parametric uncertainties are clearly revealed on the physical model through causal and structural properties of bond graph methodology since the PEMFC components are represented by elements $R, C, I, T F$, and $G Y$. Indeed, each generated uncertain residue consists of two parts: the first part corresponds to the evolution of a normal residue $\left(r_{i n}\right)$ and the second part represents the evolution related to the parameter uncertainty $\left(d_{i}\right)$.

In this paper, a technique for diagnosing a PEMFC using bond graph approach was proposed. We presented a $1.2 \mathrm{~kW}$ Nexa PEMFC bond graph model as well as a method for diagnosing uncertain parameter systems. The fault diagnostic tests showed agreement between inference results and the original fault causes. The fault diagnostic tests were effective in detecting emerging faults within the PEMFC before the appearance of a subversive impact. 


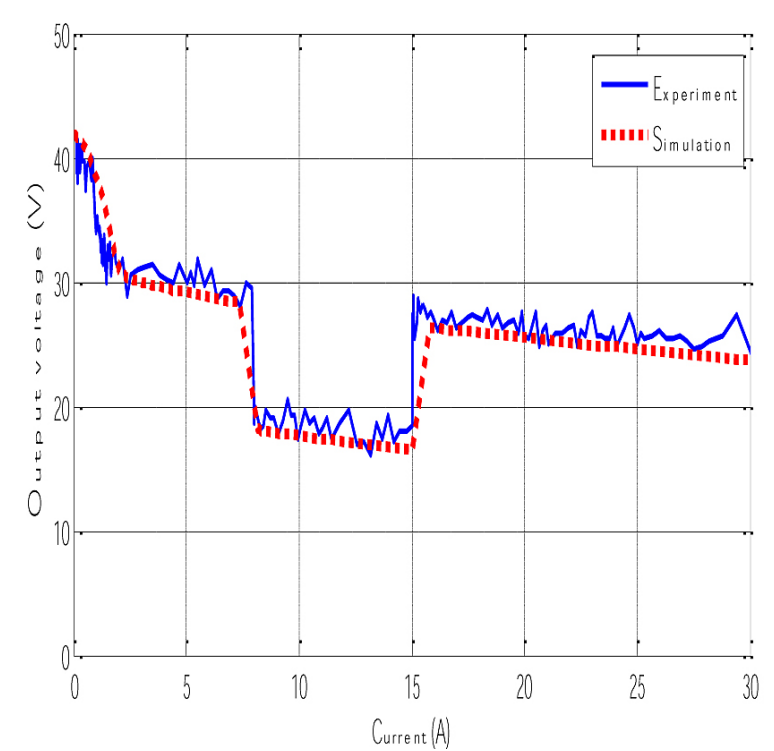

Fig. 12. Polarization curve of $1.2 \mathrm{~kW}$ Nexa fuel cell with fault in TF element due to an under-voltage

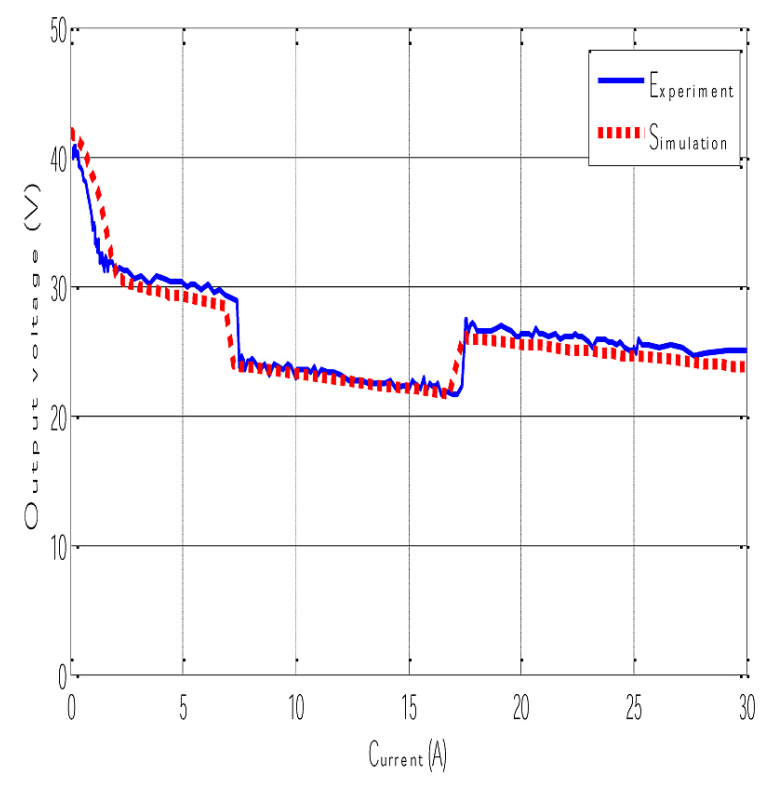

Fig. 14. Polarization curve of $1.2 \mathrm{~kW}$ Nexa fuel cell with fault in RS element due to a power shortage

\section{Acknowledgements}

We thank the National School of Engineers of Tunis, University of Tunis El Manar to support our work.

\section{REFERENCES}

1. Adrot O., Maquin D., Ragot J. Diagnosis of an uncertain static system, Proceedings of the 39th IEEE Conference on Decision and Control, Sydney, NSW, 12-15 Dec, 4150-4154.

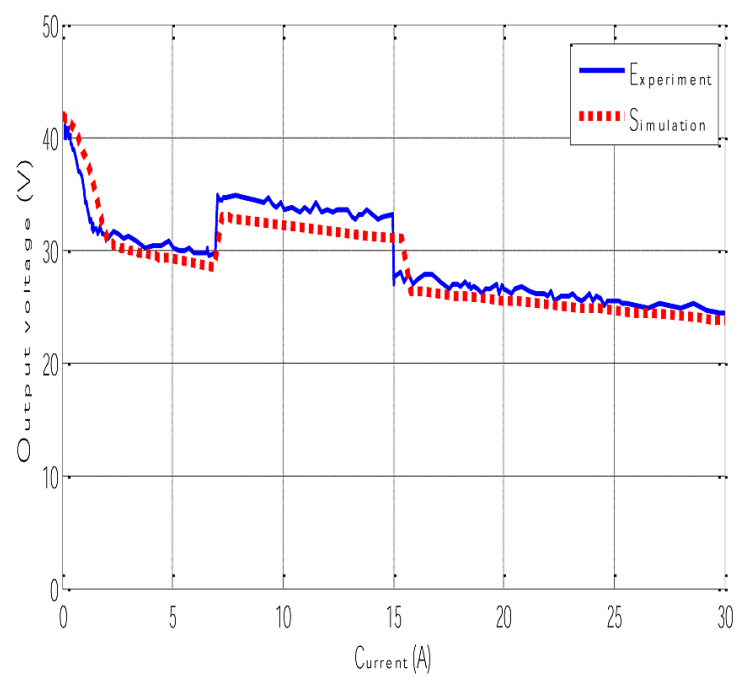

Fig. 13. Polarization curve of $1.2 \mathrm{~kW}$ Nexa fuel cell with fault in RS element due to an overcurrent

2. Borutzky W. Bond Graph Methodology Development and Analysis of Multidisciplinary Dynamic System Models, London, England: Springer-Verlag, 2010.

3. Bressel M., Ould Bouamama B., Hissel D., Hilairet M. A Review on Graphical Methods for Modeling a Proton Exchange Membrane Fuel Cell, ASME - Journal of Fuel Cell Science and Technology, 2015, Fuel Cell Sci. Technol 12(6), 060801 (Jan 20, 2016) (19 pages) Paper No: FC-14-1108; doi: $10.1115 / 1.4032336$.

4. Dauphin-Tanguy G., Kam C. How to model parameter uncertainies in a bond graph framework, European simulation symp, Erlangen, Germany, October 1999, 121-125.

5. Dauphin-Tanguy G. Les bond graphs, Paris, Fance: Hermes Science Publications, 2000.

6. Dauphin-Tanguy G., Tagina M. La méthodologie bond graph Principes et applications, Centre de Publication Universitaire, 2003.

7. Djeziri M., Ould Bouamama B., Merzouki R. Modelling and robust FDI of steam generator using uncertain bond graph model, Journal of Process Control, 2009, 19, 149-162.

8. Djeziri M., Ould Bouamama B. Reliability Analysis of Leak Detection and Isolation System. J. of Energy and Power Engineering" ISSN1934-8975, USA, 2009.

9. Djeziri M., Ould Bouamama B., Dauphin-Tanguy G. LFT Bond Graph Model Based Robust Control and Diagnosis. Book Chapter in Springer Verlag, 2011, 105-1035.

10. Hirschenhofer J., Stauffer D., Engleman R., Klett M. Fuel Cell Handbook, 4th ed. Reading, PA, USA: Parsons Corporation, 1998. 
11. Hoogers G. Fuel Cell Technology Handbook, 1st ed. USA: CRC Press, 2002.

12. Kam C., Dauphin-Tanguy G. Bond graph models of structured parameter uncertainties, Journal of the Franklin Institute, 2005, 342, 379-399.

13. Larminie J., Dicks A. Fuel Cell Systems Explained, 2nd ed., Chinchester, England: Wiley, 2003.

14. Lefebvre F. Contribution à la modélisation pour le diagnostic des systèmes complexes: application à la signalisation des lignes à grande vitesses, $\mathrm{PhD}$. Thesis, Valenciennes University, France, 2000.

15. Loureiro R., Merzouki R. and Ould Bouamama B. Bond Graph Model Based on Structural Diagnosability and Recoverability Analysis: Application to Intelligent Autonomous Vehicles. IEEE Transactions on Vehicular Technology, 2012, 61(3), 986-997.

16. Larminie J., Dicks A., Fuel Cell Systems Explained, 2nd ed., Chinchester, England: Wiley, 2003.

17. Mzoughi D., Allagui H., Bouaicha A., Mami A. Modeling and testing of a $1.2-\mathrm{kW} \mathrm{Nexa}^{\mathrm{TM}}$ fuel cell using bond graph methodology, IEEJ Transactions on Electrical and Electronic Engineering, 2015, 10, $1-14$.

18. Ould Bouamama B., Dauphin-Tanguy G.. Modelisation Bond Graph Element de base pour l'energetique. Technique de L'ingenieur, 2005, 8, 280-280.

19. Ould-Bouamama B. La conception intégrée pour la surveillance robuste des systemes. Approche Bond Graph. Techniques de l'Ingénieurs AG3550. 2013, 24 pages.
20. Ploix S., Adrot O., Ragot J. Bounding approach to the diagnosis of uncertain static systems, 4th Symposium on Fault Detection, Supervision and Safety for Technical Processes, Safeprocess'2000, Budapest, Hungary, June 2000, 151-156.

21. Paynter H. Analysis and Design of Engineering Systems, Boston, USA: MIT Press, 1961.

22. Samantary A., Medjaher K., Ould Bouamama B., Staroswiecki M., Dauphin-Tanguy G. Diagnostic bond graphs for online fault detection and isolation, Simulation Modelling Practice and Theory, 2006, 14, 237-262.

23. Samantary A., Ould Bouamama B. Model-based process supervision, London, England: SpringerVerlag, 2008.

24. Samantary A., Ghoshal S. Bicausal bond graph for supervision: from fault detection and isolation to fault accommodation, Journal of the Franklin Institute, 2008, 345, 1-28.

25. Karnopp D., Margolis D., Rosenberg R. System Dynamics: A Unified Approach, New York, NY, USA: Wiley, 1990.

26. Thoma J. Ould Bouamama B. Modelling and Simulation in Thermal and Chemical Engineering, New York, NY, USA: Springer-Verlag, 2000.

27. Touati Y., Merzouki R., Ould Bouamama B. Robust diagnosis to measurement uncertainties using bond graph approach: Application to intelligent autonomous vehicle"Mechatronics, Publisher (E1sevier), 2012, 22(8), 1148-1160.

28. 20- $\operatorname{sim}^{\mathrm{TM}}$..Controllab Products BV, Available at: <http:// www.20sim.com>, access date: 10.09.2015. 